\title{
GRADING CONTROVERSIES IN THE ASSESSMENT OF UNIVERSITY GRADUATES IN BANGLADESH
}

\author{
Ziaul Karim (Bangladesh) \\ Jamal Hossain (Bangladesh)
}

\begin{abstract}
Tertiary education has undergone several changes in the past few decades in Bangladesh. And one of the important alterations seems to be the introduction of letter grade system instead of numeric marking for assessment. Though letter grading as part of assessment is now an integral component of all the universities in Bangladesh, surprisingly this method of assessment is not consistent, even though the University Grants Commission (UGC) has provided a uniform grading scale to follow. This study attempts to find out the purposes of grading, problems with current grading practices and the impact of such discrete grading system on the learners and teachers. Finally, it suggests some ways out in order to bring harmony to the overall grading process.
\end{abstract}

KEYWORDS: Grading system, university, assessment criteria, uniformity

\section{INTRODUCTION}

Grading as a tool for student assessment plays a very significant role in teaching and learning. Therefore, it is an integral part of every academic institution. In Bangladesh, the grading criteria in all levels of schooling are more or less the same in the state-funded institutions. However, the case of private institutions, particularly the private universities is a bit different. This is because the grading criteria of those tertiary institutions are not uniform. Though a few universities follow the University Grants Commission (UGC) grading scale, a good number of them have their own assessment policy. Despite continuous demand for the common grading policy by many students, those universities seem to be adamant to go on with their discrete grading criteria. It is obvious that such distinct systems or policies of assessment may have a great impact on the motivation of their learners, because "used with skill, assessment can motivate the unmotivated, restore the desire to learn, and encourage students to keep learning, and it can actually create - not simply measure - increased achievement" (Arter, J. Chappius \& S. Chappius, 2004, p. 3).

Defining a test as "a systematic method of eliciting performance which is intended to be the basis for some sort of decision making" (p. 153), Skehan (1988) notes the tendency of testers to place an emphasis on "care and standardization in assessment in the belief that such methods of examining performance will have more to contribute to reliable measurement" (p. 153). A systematic testing com- 


\section{Crossing the Border: International Journal of Interdisciplinary Studies}

ponent and a standardized grading system are essential parts of every assessment in a programme to measure learner's aptitude, proficiency, placement, diagnosis, progress, and achievement, and provide feedback for the program evaluator(s), washback information for teachers and students, and motivational washforward implications for all concerned. However, the field of testing in general in the tertiary education in Bangladesh is full of problems and one of them is the grading controversies. This research article, on the basis of insights of expert educationists and researchers as well as the results of a pilot survey, attempts to find out the impact of discrete grading policy on learners. At the same time, it also tries to provide some solutions to the problems emerging out of this debate.

\section{THE WHAT, WHY, WHEN AND HOW OF GRADING}

Though the original purpose of grading was to improve student's greater learning and expansion of the mind, grades are more commonly now looked upon as a measure of student aptitude for outside sources and less for their self-improvement nature. An excellent definition and synopsis of the purpose of grading was established by the Faculty Council at the University of North Carolina - Chapel Hill:

Grading is the process of a teacher's arriving at and recording a summarizing, symbolic remark on the academic performance of his or her students. Grading should express neither approval nor disapproval of students as persons. ... the purpose of a grading system is to give the teacher a regular way to transmit to students, and to other persons who may be concerned with the intellectual development of students, value judgments made by the teacher. (The Educational Policy Committee, 2000, p. 6).

This description clearly states that grades are just as much for students as they are for anyone with a vested interest in the "intellectual development" of the student. While the inherent purpose of grades was the recognition of opportunities for increased learning of education, grading for the purpose of judgment has evolved to be the standard today. This could be due to large number of different individuals and bodies that rely on grades to make informed judgments of students. Brown and Knight (1994) specifically state eight different bodies that use grades including students, employers, university management, government agencies, and financing bodies (p. 13).

As the use and emphasis of grades have evolved, so too has the purpose of grades. While talking about the purpose of grading, there are two key elements that are intrinsically related to the goals and purposes of grading: reliability and validity. According to Brookhart (1999), "Grades must be both meaningful and accurate to truly be able to convey the information contained in their measurements to the appropriate audiences" (p. 23). In order for grades to be assessed as fairly as possible, grades must be both valid and reliable. Similarly, these key elements of reliability and validity are often the scrutinized factors when students feel as though an "unfair grade" was provided.

Reliability refers to the degree of accuracy in the grading procedures. More precisely, the measure of reliability interprets the consistency of a grade regardless 
of time of assessment, judgment of assessment, and form of assessment (Brookhart, 1999, p. 28). For instance, a student who takes a test in the afternoon should receive the exact same score as if he or she were given the same test earlier that morning. However, there is contradiction with this concept as the student who takes the later exam will be given more time in order to prepare for the exam or may take opportunity to ask an examinee who has already taken the test about the test content. That is why, it can be said that grades are never reliable across time.

Another feature for a grade to be reliable is that it must be the same even though different facilitators are involved in the assessment of the students. This may be challenging to handle when multiple instructors instruct the same class with objective grading procedures, but is nearly impossible with multiple instructors teaching the same class utilizing subjective grading. It is crystal clear that all instructors can come to the same conclusions when grading a purely objective test such as a multiple choice exam. But, when multiple instructors are involved in a subjective assessment like that of an essay, it is extremely difficult for all examiners to grade the students in the same manner. For an assessment to be as reliable as possible, a student should receive the same grade whether he is faced with a multiple choice, true-false, essay, or oral examination.

Another attribute of grades is validity, a measurement which makes grading meaningful and fit for its purpose. A grade is meaningful only when it is able to correctly evaluate the achievement of the student in relation to the objectives of the course. Students must understand the learning goals of the course and know how their performance will be graded against these goals. It is also significant that the tests are representative of those learning goals. Brookhart (1999) provides the glaring example of how invalid a French test would be for a Chemistry class:

Clearly the previously mentioned assessment would be low in validity, but validity also becomes an issue when different instructors teach different sections of a course with seemingly the same learning goals and also same assessments across sections. However, if the instructor feels that the learning goals set forth are not the essential elements to be learned in this class, the students may suffer by being assessed on material that is not consistent with the content they learned and thus lacking validity. (pp. 23-25)

However, it is obvious from above discussion that grading serves some important purposes. EiszIer (1983) proposed the following taxonomy of the purposes of grades:

They (a) allow agencies and institutions to make discriminations among individuals and their performance, (b) motivate learners, (c) give information to learners about the quality of their performance, (d) give limited information to the teacher about the quality of instruction, and (e) meet a variety of administrative and institutional needs related to the functioning of the institution. (as cited in Hammons \& Barnsley, 1992, p. 58)

\section{HISTORY OF GRADING}

The history of grading system goes back to some leading universities in the USA. Milton, Pollio, and Eison (1986) view: 


\section{Crossing the Border: International Journal of Interdisciplinary Studies}

Grades were first used at Yale University in the USA in 1783 and carried the titles optime (honor men), second optime (pass men), inferiores (charity passes), and pejores (unmentionables). In 1800, Yale began giving marks on a scale of 0 to 4 . Three years later, students' averaged marks ranged from 1.3 to 3.7; thus, the grade point average was born. (as cited in Hammons \& Barnsley, 1992, p. 52).

Prior to this grading method, there was a pass-fail system where no grade or marks were given except a plus (+). However, in 1883, Harvard University initiated using letter grades which immediately became very popular across the nation. But due to variation of institutional guidelines there were some problems with the range of variability and reliability of these letter grades. This resulted mainly from the problem of associating marks to pass-fail status (as cited in Hammons and Barnsley, 1992, p. 52). Later on, a 100-point scale was developed and associated to several letter grades $(\mathrm{A}, \mathrm{B}, \mathrm{C}, \mathrm{D}, \mathrm{F})$ which is nowadays widely used. However, the problem regarding the association of the marks (0 to 100) to various letter grades still continues to worry pupils at different private universities in Bangladesh since its inception in the last decade of the 20th century and the very beginning of the 21st century, as it was earlier in the USA.

In Bangladesh, grading system in secondary school certificate (SSC) exam was introduced in 2001. Earlier there was division system (i.e. $60 \%$ - above is 1 st division, $45 \%-59 \%$ is 2 nd division, $33 \%-44 \%$ is 3rd division and below $33 \%$ is Fail). In the public and in some private universities, there was also class system (i.e. $60 \%$ - above is 1 st class, $45 \%$ - $59 \%$ is 2 nd class, $33 \%$ - $44 \%$ is 3 rd class and below $33 \%$ is fail) whereas many private universities started the grading system as assessment since their birth. The recent shift from the division and class system to the grading system in many private and public universities has made not only the students but also the teachers a bit confused. Initially teachers were evaluating test scripts on the basis of division/class, resulting in a lower GPA for the students on an average.

\section{GRADING SYSTEM CONTROVERSIES}

The increasing number of private universities in Bangladesh using different grading scales for evaluation has caused a growing controversy in the field of tertiary level assessment. This raises the questions of grading inflation and deflation among the teachers, students, administrators, trainers and above all the guardians. Even though the UGC is the highest regulatory authority for all the universities including the private ones, not all private universities are following the UGC suggested grading scale.

At present, we find different modifications of letter grades at different universities and they vary a lot in plus (+) and minus (-). For instance, in some universities the highest letter grade is A, whereas in others it is A+. Again, D is considered to be the lowest passing grade after C- in some universities, but in many others there is a $\mathrm{D}+$ in between and the range of marks differ in both the highest and lowest cases. Let us have a look at how the UGC grading scale varies from some wide-ranging scales of some top private universities in Bangladesh: 
GRADING CONTROVERSIES IN THE ASSESSMENT . . .

Table 1: A comparative picture of grading discrepancy in higher education in Bangladesh

\begin{tabular}{|c|c|c|}
\hline \multicolumn{3}{|c|}{ UGC Grading Scale } \\
\hline Numerical Grade & Letter Grade & GPA \\
\hline $80 \%--100 \%$ & $\mathrm{~A}+$ & 4.00 \\
\hline $75 \%--79 \%$ & $\mathrm{~A}$ & 3.75 \\
\hline $70 \%--74 \%$ & $\mathrm{~A}-$ & 3.50 \\
\hline $65 \%--69 \%$ & $\mathrm{~B}+$ & 3.25 \\
\hline $60 \%--64 \%$ & $\mathrm{~B}$ & 3.00 \\
\hline $55 \%--59 \%$ & $\mathrm{~B}-$ & 2.75 \\
\hline $50 \%--54 \%$ & $\mathrm{C}+$ & 2.5 \\
\hline $45 \%--49 \%$ & $\mathrm{C}$ & 2.25 \\
\hline $40 \%--44 \%$ & $\mathrm{D}$ & 2.00 \\
\hline $0 \%--39 \%$ & $\mathrm{~F}$ & 0 \\
\hline & (Grading system, 2013, p. 1) \\
\hline
\end{tabular}

\begin{tabular}{|c|c|c|}
\hline \multicolumn{3}{|c|}{ PU Grading Scale } \\
\hline Numerical Grade & Letter Grade & GPA \\
\hline $90 \%--100 \%$ & A & 4.00 \\
\hline $85 \%--89 \%$ & A- & 3.70 \\
\hline $80 \%--84 \%$ & B+ & 3.30 \\
\hline $75 \%--79 \%$ & B & 3.00 \\
\hline $70 \%--74 \%$ & B- & 2.70 \\
\hline $65 \%--69 \%$ & C+ & 2.30 \\
\hline $60 \%--64 \%$ & C & 2.00 \\
\hline $55 \%--59 \%$ & C- & 1.70 \\
\hline $52 \%--54 \%$ & D+ & 1.30 \\
\hline $50 \%--51 \%$ & D & 1.00 \\
\hline $0 \%--49 \%$ & F & 0.00 \\
\hline \multicolumn{2}{|c|}{ (Grading system, 2011-2012, pp. 28-29) } \\
\hline
\end{tabular}

\begin{tabular}{|c|c|c|}
\hline \multicolumn{3}{|c|}{ EWU Grading Scale } \\
\hline Numerical Grade & Letter Grade & GPA \\
\hline $97 \%--100 \%$ & A+ & 4.00 \\
\hline $90 \%--96 \%$ & A & 4.00 \\
\hline $87 \%--89 \%$ & A- & 3.70 \\
\hline $83 \%--86 \%$ & B+ & 3.30 \\
\hline $80 \%--82 \%$ & B & 3.00 \\
\hline $77 \%--79 \%$ & B- & 2.70 \\
\hline $73 \%--76 \%$ & C+ & 2.30 \\
\hline $70 \%--72 \%$ & C & 2.00 \\
\hline
\end{tabular}




\begin{tabular}{|c|c|c|}
\hline $67 \%--69 \%$ & C- & 1.70 \\
\hline $63 \%--66 \%$ & D+ & 1.30 \\
\hline $60 \%-62 \%$ & $\mathrm{D}$ & 1.00 \\
\hline $0 \%-59 \%$ & $\mathrm{~F}$ & 0.00 \\
\hline \multicolumn{2}{|c|}{ (Grading system, 2008, p. 1) } \\
\hline
\end{tabular}

The tables above prove that drastic and urgent measures need to be taken to establish a balanced grading system in the tertiary education by mitigating the systematic loopholes.

There goes a continuous debate among teachers on what they should measure while grading their learners. Some teachers view that they should assess students' understanding of a course content only, whereas others say that the effort their learners put forth for studying a course also should be evaluated while grading them. The first group of teachers note that if a student gets more grade than he/she deserves for understanding a course material, it will give him/her a false representation of what he/she actually achieved in that specific course. The second group of them express that there should be some sense of flexibility in grades. Another opinion related to this issue is distribution of same handouts, lecture notes and objectives to all sections of students. (Epstein, 2006, p. 1)

There is also debate about the above two concepts in Bangladesh. As teachers get no straight forward guidelines regarding these issues, they depend on their whim while grading students. Some teachers follow the first group while those who are against them favour the second. So, it is high time teachers came out of the grading controversies and as a remedy the UGC needs to play an important role by training teachers on grading and of course by implementing a uniform grading scale for all the universities in Bangladesh.

\section{RESEARCH METHODOLOGY AND SAMPLING Participants}

Participants included 17 teachers and 89 students of different departments from four private universities named Independent University Bangladesh (IUB), World University of Bangladesh (WUB), Presidency University (PU) and Ishakha International University Bangladesh (IIUB). Among teacher respondents 5 (2 male and 3 female) were from IUB and out of them 4 were from English department and 1 from Media Communications; 4 English department teachers ( 3 male and 1 female) from WUB; 3 English department teachers ( 2 male and 1 female) from PU and 5 male teachers ( 2 from Law, 2 from Business and 1 from English departments) from IIUB. Among the students 49 (33 male and 16 female) were from the departments of Business (32), Engineering (10), Environmental Science (6) and English (1) at IUB; 20 (9 male and 11 female) from the English department of WUB and 20 from the departments of Business (14) and English (6) at PU.

\section{Materials}

Two separate questionnaires were designed to elicit information from both 
the teachers and students. The questionnaire for teachers included 13 questions whereas that of the students included 15 . The options to the questions were designed following five-point Likert-scale ranging from (a) strongly agree to (e) strongly disagree excepting only one question (Q-7) where the five-point scale ranged from (a) very standard to (e) unsatisfactory.

\section{Procedures}

Simple random technique has been applied as sampling procedure. Simple Random Sampling from a finite population refers to that "method of sample selection, which gives each possible sample combination an equal probability of being picked up and each item in the entire population to have an equal chance of being included in the sample" (Kothari, 1996. p. 60). The respondents were given the questionnaires to fill out with the options like name, age, sex, department and university name on top of the questionnaires.

\section{THE SURVEY RESULTS}

There were 15 questions in the questionnaire prepared for students and 13 for teachers. And most of the questions invited same feedback from them. These questions surveyed the views of the participants about grading imbalance, its impact on students and other related issues. We got some mixed responses from our respondents. While most of the students (46\%) strongly agreed, the highest number of teachers (59\%) simply agreed that there is grading imbalance in the private universities in Bangladesh, in response to the first question. Next, whereas the highest number of students (64\%) strongly agreed, the highest no. of teachers (47\%) simply agreed to the view that grading imbalance affects students in the job market which is a very vital issue. After that, most of the participants ( $88 \%$ teachers and $50 \%$ students) viewed strongly that discriminatory grading policies need to be avoided and at the same time a uniform grading policy should be introduced. In response to the fourth question, $53 \%$ teachers and $60 \%$ students, the highest, agreed that professional training on assessment criteria is necessary for teachers. Then $65 \%$ teachers and 53\% students strongly agreed that they should have knowledge about the UGC grading policy. But most of the students did not know anything about it. In response to the sixth question the highest number of teacher (47\%) and student (58\%) respondents agreed that they should have knowledge of relative grading. However, it is a vague thing to many students as well as teachers.

However, it seems unusual to us that in spite of having knowledge about discrete grading policies most of the students (55\%) viewed that their institution's grading scale was standard. Anyway, in response to their seventh question the highest no. of teacher participants (53\%) strongly agreed that assessment is a very important part of teaching and learning. And in answering to the same question, most of the students (38\%) agreed that assessment is an important part of teaching and learning. Here we find that the views of students and teachers vary to some extent.

Next, 53\% teachers and 52\% students, the highest, strongly agreed that better institutional assessment policy motivates students for learning. After that the 


\section{Crossing the Border: International Journal of Interdisciplinary Studies}

highest no. of students (67\%) agreed to the point, "Institutional assessment has impact on students' lekarthhgarning."

It is a very important point to note that the highest no. of students (62\%) agreed whereas most of the teachers (47\%) strongly agreed that every institution needs to ensure that the assessment procedures address the course objectives and provide an appropriate mechanism to assess its students' learning and understanding. This indicates their awareness of the relationship between assessment and teaching and learning. Similarly, the highest number of student respondents (56\%) agreed and most of the teacher participants (29\%) strongly agreed that learners' cultural diversity, socio-economic differences, gender and disability need to be considered during assessment.

Afterwards most of the students (58\%) and teachers (47\%) strongly supported that at the beginning of course, teachers need to state all forms of assessment workload in the course outline including details of contact hours and assessment types according to the university policy. Then, the highest no. of student (50\%) and teacher (47\%) participants strongly viewed that teachers also need to develop grading criteria on discussion with their students. The last question was about reliability and fairness of institutional assessment. This is completely an ethical issue for the teachers. And most of the participants (55\% students and 70\% teachers) strongly supported the view that institutional assessment methods should ensure reliability and fairness to all students. This indicates that teachers are very conscious of their ethical responsibilities while grading their learners. Thus, it is obvious that none of the questions elicited any response contradictory to our general views or ideals of grading criteria or policies.

\section{FINDINGS}

From our survey, among the students and teachers, we found some important issues to be considered for grading. These are:

- There is grading imbalance in the private universities in Bangladesh and it affects the graduates in the job market. Therefore, discriminatory grading policies need to be avoided and a uniform grading policy should be introduced.

- Both teachers and students should have idea about the UGC grading scale. They also need to have knowledge about relative grading.

- Institutional assessment needs to be standard as well as satisfactory to its learners. This is because assessment has impact on students' learning and better assessment policy acts as a motivating factor for the students.

- Grading as a part of assessment is an important part of teaching and learning.

- Every institution needs to ensure that the assessment procedures address the course objectives and provide an appropriate mechanism to assess its students' learning and understanding.

- While grading students, teachers need to consider students' cultural diversity, socio-economic differences, gender, and disability.

- Teachers need to develop grading criteria (i.e. how marks will be given or deducted for content, cohesion \& coherence, spelling mistakes, grammar, etc.) on discussion with their students. They also need to state all forms of as- 
sessment workload in the course outline at the beginning of the course, and include details of contact hours and assessment types following the university policy.

- Finally, institutional assessment methods should ensure reliability and fairness to all students.

\section{SELECTING A UNIFORM GRADING APPROACH}

Vice-chancellors of all universities in Bangladesh, both in the public and private sectors, have agreed in principle to implement a uniform grading system to ensure standardization of the university degrees they offer. The University Grants Commission (UGC) sent the recommendations to the Ministry of Education, proposing a uniform grading system and suggesting ways to implement it in all the universities, local daily New Age reported on Sunday. (Uniform grading system for all universities agreed in Bangladesh, 2005, p. 1)

The initiatives to formulate the uniform grading system were taken following a controversy over the variety of evaluation systems among the universities, even in different departments or institutions at the same university. However, that uniform grading scale is not being followed by many universities.

Abul Quasem Haider, chairman, Eastern University and vice chairman, Association of Private Universities of Bangladesh in 2008 in an article on "Please for reforming grading system" published in The Financial Express on August 15, 2008, mentioned that most of the government-run universities have introduced the UGC grading system while a good number of private universities are yet to introduce it. The universities that earlier followed the North American 'curriculum' are continuing with a different grading system that was introduced earlier. He also reports:

Introduction of UGC's Integrated Grading System would create an acute problem in future for the students intending to go to North America for higher education. This integrated grading system will not be acceptable to North American universities which treat 90 and above marks as grade 'A'. Moreover, there is no 'A+' in the North American universities. So, it is likely to create a complication regarding grading when a student from Bangladesh would send his or her transcript to a North American university seeking admission. It is, therefore, necessary to review the grading system devised by the UGC, especially for the universities. (Haider, 2008, p. 1)

He suggests that it would be better if the UGC grading is revised following the curriculum of the North American universities.

As there is a strong demand on the necessity of a uniform grading system, it may be suggested that the authority would look into the matter and form a national level committee, with reputed personalities and experienced educationists to revise and implement an international standard system of uniform grading for all the universities in Bangladesh. 


\section{CONCLUSION}

In this paper we tried to find out the current status of the grading system in the tertiary private education in Bangladesh. The encouraging discovery is that both the teachers and students are quite aware of the fact of grading imbalance in the private universities and everybody demands uniformity in the grading scale for all the universities in Bangladesh.

\section{REFERENCES}

Arter, J. A., Chappuis, J. \& Chappuis, S. (2004). Classroom Assessment for Student Learning: Doing It Right, Using It Well. Oregon: Assessment Training Institute. Brookhart, S. (1999). The Art and Science of Classroom Assessment: The Missing Part of Pedagogy. ASHE-ERIC Higher Education Report (Vol. 27, No. 1).

Washington DC: George Washington University.

Brown, S. \& Knight, P. (1994). Assessing Learners in Higher Education. London: Kogan Page.

Epstein, D. (2006). A Different Take on Classroom 'Fairness'. Inside Higher Ed. http://www.insidehighered.com/news/2006/01/27/grading [18 Apr. 2013]. Grading system (2011-2012). Student Handbook: Department of English. Dhaka: Presidency University.

Grading system (2013). University Grants Commission of Bangladesh. http://www.ugc.gov.bd/grading_system/ [3 April, 2013]

Grading system (2008). Examination Rules.

http://www.ewubd.edu/ewu/showDocument.php?documentid=1043 [7 May 2013] Haider, A. Q. (2008, Aug. 15). Pleas for reforming grading system. The Financial Express. http://www.thefinancialexpress-bd.com/2008/08/15/42697.html [10 Apr. 2013]

Hammons, J. O., \& Barnsley, J. R. (1992). Everything you need to know about developing a grading plan for your course (well, almost). Journal on Excellence in College Teaching 3, 51-68.

Kothari, C. R. (2004). Research Methodology: Methods and Techniques (2nd ed.).

New Delhi: New Age International Publishers.

Skehan, P. (1988). A Cognitive Approach to Language Learning. Oxford: Oxford U.P. The Educational Policy Committee (2000). Grade Inflation at UNC - Chapel Hill: A Report to the Faculty Council. 1-24.

http://www.unc.edu/faculty/faccoun/reports/1999-00/R2000EPCGrdInfl.PDF [10 Apr. 2013].

Uniform grading system for all universities agreed in Bangladesh (2005, Dec. 25). People's Daily Online.

http://english.peopledaily.com.cn/200512/25/eng20051225_230697.html.

[12 Apr. 2013] 


\section{APPENDIX-1: QUESTIONNAIRE FOR STUDENTS}

This questionnaire is part of an academic research. Your response will contribute greatly to this endeavour. The information you provide will be kept confidential.

Name:

Sex: $\quad$ Male $\quad$ Female

Age:

Department:

University:

Please tick the correct option(s):

1. There is grading imbalance in the private universities in Bangladesh.
a. Strongly agree
b. Agree
c. Neither agree nor disagree
d. Disagree
e. Strongly disagree

2. Grading imbalance affects the students in the job market.
a. Strongly agree
b. Agree
c. Neither agree nor disagree
d. Disagree
e. Strongly disagree

3. Discriminatory grading policies need to be avoided and a uniform grading policy should be introduced.
a. Strongly agree
b. Agree
c. Neither agree nor disagree
d. Disagree
e. Strongly disagree

4. Professional training on assessment criteria and policies is necessary for teachers.
a. Strongly agree
b. Agree
c. Neither agree nor disagree
d. Disagree
e. Strongly disagree

5. Students should have idea about the University Grants Commission (UGC) grading scale.
a. Strongly agree
b. Agree
c. Neither agree nor disagree
d. Disagree
e. Strongly disagree 
6. Students should have knowledge about relative grading.
a. Strongly agree
b. Agree
c. Neither agree nor disagree
d. Disagree
e. Strongly disagree

7. What is your evaluation of your institutional assessment (i.e. marks, grades, etc)?
a. Very Standard
b. Standard
c. Neither standard nor satisfactory
d. Satisfactory
e. Unsatisfactory

8. Institutional assessment is a very important part of teaching and learning.
a. Strongly agree
b. Agree
c. Neither agree nor disagree
d. Disagree
e. Strongly disagree

9. Better institutional assessment policy motivates students for learning.
a. Strongly agree
b. Agree
c. Neither agree nor disagree
d. Disagree
e. Strongly disagree

10. Institutional assessment has impact on students' learning.
a. Strongly agree
b. Agree
c. Neither agree nor disagree
d. Disagree
e. Strongly disagree

11. Every institution needs to ensure that the assessment procedures address the course objectives and provide an appropriate mechanism to assess its students' learning and understanding?
a. Strongly agree
b. Agree
c. Neither agree nor disagree
d. Disagree
e. Strongly disagree

12. Every institution needs to ensure that assessment items should consider students' cultural diversity, socioeconomic differences, gender, and disability.
a. Strongly agree
b. Agree
c. Neither agree nor disagree
d. Disagree
e. Strongly disagree 
13. Teachers need to state all forms of assessment workload in the course outline and in discussion at the beginning of the course, and include details of contact hours and assessment types in accordance with the University Policy.
a. Strongly agree
b. Agree
c. Neither agree nor disagree
d. Disagree
e. Strongly disagree

14. Teachers need to develop grading criteria (i.e. how marks will be given or deducted for content, cohesion \& coherence, spelling mistakes, grammar, etc.) along with his/her students (in class or on-line).
a. Strongly agree
b. Agree
c. Neither agree nor disagree
d. Disagree
e. Strongly disagree

15. Institutional assessment methods should ensure reliability and fairness to all students.
a. Strongly agree
b. Agree
c. Neither agree nor disagree
d. Disagree
e. Strongly disagree

\section{APPENDIX-2: QUESTIONNAIRE FOR TEACHERS}

This questionnaire includes 13 questions with the same options. The only differences are in questions $5 \& 6$ where 'students' is replaced with 'teachers' in the subject position of the statement sentences. Question nos. 7 and 10 in the students' questionnaire are omitted from the teachers'.

\section{ABOUT THE AUTHORS}

Ziaul Karim is an Assistant Professor of English in the Department of Languages at Bangladesh Agricultural University, Mymensingh. He worked as a full time faculty in the Department of English at Presidency University and as an adjunct one in Independent University Bangladesh and Southeast University. He was a Consultant for Survival English at International Organization for Migration (IOM) and conducted an English Language Skills Development course for some engineers at $I C D D R, B$. He also earned experience as an English Medium teacher by working at Touheed's Academy and Green Dale International School in Dhaka. He took parttime classes as a Spoken English teacher at Hermann Gmeiner College and Future Commerce College in Dhaka as well. He worked as an Executive Committee Member of Bangladesh English Language Teachers Association (BELTA). He obtained his Bachelor and Master degrees from the Department of English, Dhaka University. Later on he achieved certificates on TESOL from the University of South Carolina 
and on 'Teaching Language Skills through the Interactive Web" from the University of Oregon, USA. Email: ziaul007_karim@yahoo.com

Jamal Hossain is an Assistant Professor in the Department of English, Presidency University, Dhaka, Bangladesh. He is the current Treasurer (2013-2014) of Bangladesh English Language Teachers Association (BELTA). He has been involved with this association for the last six years and has worked in several management committees responsible for organizing different national and international seminars, workshops and conferences. He took part in a good number of teacher training workshops and seminars. He presented research papers in four international conferences held in Kathmandu, Bangkok, Dhaka, and Johor. His research papers have been published at home and abroad. His areas of interests in ELT include materials development, assessment, and ESP. Md. Jamal Hossain completed his BA (Honours) in English and MA in English Literature from Dhaka University. He also completed online certificate courses on TESOL from the University of South Carolina and ESP from the University of Oregon. He is pursuing his PhD at the Department of English at Dhaka University at present. Email: jamalbb403@yahoo.com 